\title{
MONEY LAUNDERING, PUBLIC BENEFICIAL OWNERSHIP REGISTERS AND THE BRITISH OVERSEAS TERRITORIES: THE IMPACT OF THE SANCTIONS AND MONEY LAUNDERING ACT 2018 (UK)
}

\author{
John Hatchard*
}

\section{INTRODUCTION}

The revelations from the Panama Papers ${ }^{1}$ have highlighted the potential use of off-shore shell and shelf companies based in the British Overseas Territories and Crown Dependencies to facilitate money laundering, tax evasion, the financing of terrorism and other serious and organised crime. The use of such companies has enabled the natural person(s) who ultimately owned or controlled the company to remain concealed behind a nominee director(s) and nominee shareholder(s). ${ }^{2}$ This has led to international interest and pressure to increase the transparency in the beneficial ownership of such companies.

This note explores the important recent developments towards enhancing beneficial ownership transparency, especially as regards the United Kingdom (UK) and its Overseas Territories (OTs) and Crown Dependencies (CDs). It is divided into five sections. This section provides an introduction and background to the issue. Section 2 reviews some of the ongoing international efforts aimed at improving transparency in beneficial ownership and that is spearheaded by the Financial Action Task Force and the G20. Section 3 considers beneficial ownership transparency

\footnotetext{
* Professor, School of Law, University of Buckingham. Email: john.hatchard@buckingham.ac.uk

${ }^{1}$ For details, see the website of the Consortium of Investigative Journalists

$<$ https://www.icij.org/> accessed 20 July 2018.

2 The Conference of State Parties to the United Nations Convention against Corruption, Report of the International Group Meeting on Beneficial Ownership (CAC/COSP/2017/CRP.5) para 32, also notes that corruption schemes increasingly use new sophisticated types of corporate vehicles with so-called "tax havens or secrecy jurisdictions" being used to facilitate the criminality.
} 
and law enforcement cooperation with reference to the UK, OTs and CDs. Section 4 then focuses on the development of public registers of the beneficial ownership of companies in the OTs following the passing of the Sanctions and Money Laundering Act 2018. The final section contains a short conclusion.

There are 14 Overseas Territories including Anguilla, Bermuda, the British Virgin Islands, Cayman Islands, Gibraltar and the Turks \& Caicos Islands ${ }^{3}$ whilst the Crown Dependencies comprises the Bailiwick of Guernsey, the Bailiwick of Jersey and the Isle of Man. ${ }^{4}$ All are of international significance as offshore financial centres. Yet, as Nicholls et al have pointed out, there has been "persistent criticism of the offshore financial sector ... since there exist jurisdictions in which legal frameworks and practices obscure the identity of beneficial owners by, for example, placing ownership in the hands of nominee directors and shareholders". ${ }^{5}$ Indeed the UK National Crime Agency has reportedly calculated that $£ 90$ billion is laundered through the UK each year and that "this laundering can only be done, by and large, through British overseas territories, which are central to this nefarious activity". ${ }^{6}$

The use of off-shore shell and shelf companies to purchase expensive real estate was highlighted in a 2014 study by Transparency International which found that 9.3 per cent of properties in the City of Westminster, 7.3 per cent in Kensington \& Chelsea, and 4.5 per cent in the City of London were owned by shell companies registered in an offshore "secrecy" jurisdiction. ${ }^{7}$ The study further revealed that 36,342 London properties

${ }^{3}$ The full list is set out in the British Nationality Act 1981, sch 6. For a useful historical survey of the Caribbean OTs see Peter Clegg, 'Non-self-governing Territories of the Caribbean and Debates over Autonomy' in J West (ed), South America, Central America and the Caribbean 2016 (24 $4^{\text {th }}$ edn, Routledge 2016) 33-39: available at <http://eprints.uwe.ac.uk/27446/3/sac.essay.21.2.pdf> accessed 10 July 2018. For a useful history of the OTs see Foreign \& Commonwealth Office, Overseas Territories: Security, Success and Sustainability (White Paper, Cm 8374, 2012).

${ }^{4}$ Within the Bailiwick of Guernsey there are three separate jurisdictions: Guernsey (which includes the islands of Herm and Jethou); Alderney; and Sark (which includes the island of Brecqhou).

${ }^{5}$ Colin Nicholls and others, Corruption and Misuse of Public Office $\left(3^{\text {rd }}\right.$ edn, OUP 2017) para 23.04.

${ }^{6}$ Andrew Mitchell MP in the House of Commons debate of the Report Stage of the Sanctions and Anti-Money Laundering Bill Deb 1 May 2018, 42.

${ }^{7}$ Transparency International, Corruption on your doorstep: How corrupt capital is used to buy property in the UK (Transparency International, 2014) 16. 
were held by offshore companies with the vast majority being registered in the OTs and CDs. ${ }^{8}$

The Organisation for Economic Cooperation and Development (OECD) has defined shell companies as: “... entities established not to pursue legitimate business activity but solely to obscure the identity of their beneficial owners and controllers" 9 and noted further that a shell company functions as a corporate veil, providing an effective screen separating criminals from illicit financial activities. Findlay has also commented that "Shell companies that cannot be linked back to the real individuals in control create near-insuperable obstacles for regulators and law enforcement officials". ${ }^{10}$ "Shelf companies" have also been identified as posing a particular problem as they "provide individuals with a company history and a set of company officials unrelated to the corrupt individual". ${ }^{11}$

In this context, a beneficial owner is defined in the Financial Action Task Force (FATF) Recommendations as follows:

"Beneficial owner refers to the natural person(s) who ultimately owns or controls a customer and/or the natural person on whose behalf a transaction is being conducted. It also includes those persons who exercise ultimate effective control over a legal person or arrangement". ${ }^{12}$

Reflecting the often complex ownership and control structures of companies, the FATF Recommendations add:

"Reference to "ultimately owns or controls" and "ultimate effective control" refer to situations in which ownership/control is

\footnotetext{
${ }^{8}$ Ibid 5. More than one third of all foreign companies holding London property were incorporated in the British Virgin Islands (13,831 properties), Jersey 14\% (5,960 properties), the Isle of Man 8.5\% (3,472 properties) and Guernsey 8\% (3,280 properties).

${ }^{9}$ OECD Steering Committee on Corporate Governance, Behind the Corporate Veil: Using Corporate Entities for Illicit Purposes (Paris, 2001) 17.

${ }^{10}$ Michael Findlay, Daniel Neilson and Jason Sharman, 'Global Shell Games: Testing Money Launderers' and Terrorist Financiers' Access to Shell Companies' (Centre for Governance and Public Policy, 2012) $5<$ http://www.gfintegrity.org/wp-content/uploads/2014/05/Global-Shell-Games2012.pdf $>$ accessed 20 July 2018.

${ }^{11}$ CoSP (n 2) para 50.

${ }^{12}$ Glossary to the FATF Recommendations.
} 
exercised through a chain of ownership or by means of control other than direct control". ${ }^{13}$

Thus the need to identify the beneficial ownership of companies, (and not just shell and shelf companies), has become of international and national significance in the fight against serious crime.

\section{INTERNATIONAL EFFORTS TO IMPROVE TRANSPARENCY}

International efforts to improve the transparency and availability of beneficial ownership information are of relatively recent origin and have particularly focused on the work of the Financial Action Task Force and the G20. ${ }^{14}$

\subsection{The Financial Action Task Force (FATF)}

The FATF is an inter-governmental body comprising 37 members. However, through its system of FATF-style regional bodies, some 190 countries are now members of the FATF "family". Its role is to set internationally recognised standards to combat money laundering and this is done through the FATF Recommendations..$^{15}$ In 2003 the FATF for the first time addressed the issue of beneficial ownership and in particular the need for "competent authorities" 16 to have access to beneficial ownership information for the purpose of investigation and prosecution. The most recent set of FATF Recommendations are the International Standards on

\footnotetext{
13 Ibid.

${ }^{14}$ Another key player is the Global Forum on Transparency and Exchange of Information for Tax Purposes. The Global Forum is "an international body for ensuring the implementation of the internationally agreed standards on tax transparency and exchange of information in the tax area": see $<$ https://www.oecd.org/tax/transparency/about-the-global-forum/> accessed 15 July 2018.

${ }^{15}$ See further $<$ http://www.fatf-gafi.org/> accessed 25 July 2018. The UK is a member of FATF. The OTs and CDs are not members but are subject to assessment as to their compliance with the FATF Recommendations.

16 "Competent authorities" refers to "all public authorities with designated responsibilities for combating money laundering and/or terrorist financing". This includes law enforcement and prosecutorial authorities, supervisory authorities, tax authorities and financial intelligence units: see the Glossary to the FATF Recommendations.
} 
Combating Money Laundering and the Financing of Terrorism \& Proliferation (the FATF Recommendations). Published in 2012 they contain (amongst many other things) "essential measures" that all members of the FATF "family" are required to have in place "to enhance the transparency and availability of beneficial ownership information of legal persons and arrangements". In particular, Recommendation 24 states that:

"Countries should [must] ${ }^{17}$ ensure that there is adequate, accurate and timely information on the beneficial ownership and control of legal persons that can be obtained or accessed in a timely fashion by competent authorities....". ${ }^{18}$

Further, an Interpretive Note to Recommendation 24 states that:

"Competent authorities should [must] be able to obtain, or have access in a timely fashion to, adequate, accurate and current information on the beneficial ownership and control of companies and other legal persons (beneficial ownership information) that are created in the country".

As regards trusts, Recommendation 25 states that countries "should [must] ensure that there is adequate, accurate and timely information on express trusts, including information on the settlor, trustee and beneficiaries that can be obtained or accessed in a timely fashion by competent authorities". ${ }^{19}$

Improving the transparency and availability of beneficial ownership information remains a high priority, especially as few countries, including

\footnotetext{
${ }^{17}$ The Glossary to the FATF Recommendations states that "For the purposes of assessing compliance with the FATF Recommendations, the word "should" has the same meaning as "must"،

${ }^{18}$ The Fourth European Union (EU) Money Laundering Directive was published in 2015 and reflects the additional AML obligations contained in the FATF Recommendations. EU Member States were required to implement the Directive by June 2017 .

${ }^{19}$ In 2014 the FATF published its Guidance on Transparency and Beneficial Ownership. This requires States to ensure that measures are in place to: prevent legal persons or arrangements from being used for criminal purposes; make legal persons/arrangements sufficiently transparent; and ensure that accurate and up-todate basic and beneficial ownership information is available on a timely basis.
} 
G20 countries, have effective cooperation mechanisms in place..$^{20}$ Clearly, this remains work in progress. It might also be noted that the focus of the FATF is on law enforcement cooperation and there is no mention in the FATF Recommendations of the need for member countries to establish a public register of beneficial ownership of companies or trusts.

\subsection{G20}

The G20 is an informal group of 19 countries and the European Union that addresses issues relating to international economic cooperation. Reducing corruption remains a high priority and at its 2014 meeting in Australia the G20 High-Level Principles on Beneficial Transparency Ownership (the Principles) were agreed. These are a set of "core principles on the transparency of beneficial ownership of legal persons and arrangements and are built on existing international instruments and standards". ${ }^{21}$ The Principles include the following:

1. Countries should have a definition of "beneficial ownership" that captures the natural person(s) who ultimately own or control the legal person or legal arrangement;...

3. Countries should ensure that legal persons maintain beneficial ownership information onshore and that information is adequate, accurate and current;

4. Countries should ensure that competent authorities (including law enforcement and prosecutorial authorities, supervisory authorities, tax authorities and financial intelligence units) have timely access to adequate, accurate and current information regarding the beneficial ownership of legal persons and legal arrangements.

Again, there is no reference to a requirement for states to introduce a public register of beneficial ownership.

20 The FATF has reported that to date (July 2018) “... few countries have demonstrated that information is available to competent authorities on the beneficial owner of legal persons and arrangements, or that these persons and arrangements are prevented from being misused." FATF Report to the G20 Finance Minister and Central Bank Governors (Paris, 2018) para 23 $<$ https:/www.fatf-gafi.org/media/fatf/documents/reports/FATF-Report-G20-FMCBG-July-2018.pdf $>$ accessed 27 July 2018.

${ }^{21}<$ www.g20.org/sites/default/files/media/g20_highlevel_principles_on_beneficial_ownership_transparency.pdf $>$ accessed 15 July 2018 . 


\section{BENEFICIAL OWNERSHIP TRANSPARENCY AND LAW ENFORCEMENT COOPERATION: THE UK, OTS AND CDS}

\subsection{The constitutional relationship between the UK, OTs and CDs}

Examining the constitutional relationship between the UK and the OTs and the UK and the CDs respectively is fundamental to an understanding of recent developments concerning beneficial ownership transparency.

The relationship between the UK and the OTs is set out in a 2012 UK Government White Paper entitled Overseas Territories: Security, Success and Sustainability (the OT White Paper):

"The UK, the Overseas Territories and the Crown Dependencies form one undivided Realm.... Each Territory has its own Constitution and its own Government and has its own local laws. As a matter of constitutional law the UK Parliament has unlimited power to legislate for the Territories. Territory Constitutions set out the powers and responsibilities of the institutions of government, which for most Territories include a Governor or Commissioner, an elected legislature and Ministers. Governors or Commissioners are appointed by Her Majesty The Queen on the advice of Her Ministers in the UK, and in general have responsibility for external affairs, defence, internal security (including the police) and the appointment, discipline and removal of public officers. Elected governments have a wide range of responsibilities" (my emphasis).

The italicised words are crucial as they emphasise that the Crown retains a residual power to legislate for the OTs. Indeed this is specifically provided for in some constitutions of the OTs. For example, section 125 of the Cayman Islands Constitutional Order 2009 states: "There is reserved to Her Majesty full power to make laws for the peace, order and good government of the Cayman Islands". 22 The exercise of this power is normally undertaken by means of an Order in Council. Responsibility for the OTs falls on the UK Foreign \& Commonwealth Office.

\footnotetext{
22 SI No 1379. See also the Turks \& Caicos Constitutional Order 2011 that is noted below. Such Orders may be subject to judicial review: $R$ (Bancoult) $v$ SoSFCA (No 2) [2008] UKHL 61, [2009] AC 453.
} 
The CDs have a very different constitutional history. The Channel Islands (and probably the Isle of Man) have never been a colony or conquered or ceded territory and they are not part of the United Kingdom administratively or legally. ${ }^{23}$ Further, they have never had any parliamentary representation in the House of Commons. ${ }^{24}$ They are selfgoverning dependencies of the Crown with their own directly elected legislative assemblies, administrative, fiscal and legal systems and law courts. ${ }^{25}$ The UK Ministry of Justice, Crown Dependencies Branch, is responsible for managing the constitutional relationship with the CDs. ${ }^{26}$

As regards UK legislation, the position is as follows:

\section{"UK legislation rarely extends to the Crown Dependencies and should not be extended without first consulting the Islands"}

${ }^{23}$ Guernsey and Jersey were originally part of the Duchy of Normandy when Duke William, following his conquest of England in 1066, became King William I of England. In 1204 when King John lost Normandy to the French, the islands elected to remain loyal to the English Crown. The Isle of Man first came under the English Crown in 1399, in circumstances which arguably suggest that it is a conquered territory. The point is of no significance today. See generally Ministry of Justice, Background briefing on the Crown Dependencies: Jersey, Guernsey and the Isle of Man (no date) <www.justice.gov.uk/downloads/about/moj/ourresponsibilities/Background_Briefing_on_the_Crown_Dependencies2.pdf $>$ accessed 20 July 2018.

${ }^{24}$ This provides the basis for an argument that the principle that there should be no legislation without representation undermines the power of the UK parliament to legislate for the CDs: see Protocol to the European Convention of Human Rights, art 3; Mathews v United Kingdom (1999) 28 EHRR 361. A similar argument might be made in respect in the OTs.

${ }^{25}$ See $R$ (Barclay) v Secretary of State for Justice [2014] UKSC 54, [2015] AC 276. As Lady Hale, giving the judgment of the Supreme Court noted: "Not being part of the United Kingdom, unlike Wales, Scotland and Northern Ireland, the Bailiwicks are not represented in the Parliament of the United Kingdom. They are economically self-sufficient. They pay no taxes to the United Kingdom and they receive no contribution from the revenues of the United Kingdom. They were not settled by, or conquered by or ceded to, the United Kingdom as colonies. Their link with the United Kingdom and the rest of the Commonwealth is through the Crown, not in the sense of the ultimate executive authority in the United Kingdom, but in the sense of the person of the Sovereign. The Sovereign's personal representative in each Bailiwick is the Lieutenant Governor" [8].

${ }^{26}$ This involves a variety of different responsibilities including involvement in key Crown Appointments, processing legislation for Royal Assent and issuing Letters of Entrustment authorising Crown Dependency Governments to negotiate and conclude international agreements. 
Authorities and obtaining their consent. In instances where it does extend, it may do so either by virtue of the Act itself or by Order in Council made with their agreement under an enabling provision contained in the Act which provides for it to be extended to the Crown Dependencies" (my emphasis). ${ }^{27}$

The highlighted words emphasise that UK legislation does not normally extend to the CDs and in any event requires prior consultation with, and consent from, each of them. ${ }^{28}$ It seems doubtful that an Order in Council made under the prerogative could be effective in respect of domestic matters in the CDs without the consent of the local legislatures. ${ }^{29}$

\subsection{Law enforcement cooperation between the UK, OTs and CDs}

A recent United Nations report has noted that "from a law enforcement perspective, the abuse of "foreign" corporate vehicles that are incorporated outside the main jurisdiction where the $\ldots$ offence was committed constitutes the greatest problem, as it requires international cooperation" ${ }^{30}$ This is particularly significant in that for the purposes of mutual legal assistance requests, each of the OTs and CDs is a separate jurisdiction.

At the 2016 London Anti-Corruption Summit, the then British Prime Minister, David Cameron, proposed greater compliance by the OTs and CDs to provide UK tax and law enforcement authorities with access to

\footnotetext{
${ }^{27}$ UK Ministry of Justice 'Factsheet on the UK's relationship with the Crown Dependencies' (2014)

$<$ https://assets.publishing.service.gov.uk/government/uploads/system/uploads/att achment_data/file/696152/crown-dependencies-factsheet.pdf $>$ accessed 17 July 2018. This reflects the position set out, for example in the States of Jersey Law 2005 , art 31.

${ }^{28}$ For a helpful discussion on the constitutional relationship see Michael Birt, 'The power of the UK to legislate for the Crown Dependencies without consent: Fact or fiction?' (2017) 21(2) Jersey and Guernsey Law Review 152.

29 This point is beyond the scope of this note. The issue is explored by Birt who argues that the only circumstances where the prerogative power could be exercised contrary to the wishes of the legislature in a CD would be where there has been a grave breakdown in law and order. In any other circumstance, it would be unreasonable and subject to judicial review, applying Bancoult (n 23); ibid 161-162.

${ }^{30}$ CoSP report (n 2) para 33.
} 
company ownership records. In April 2016 this resulted in an Exchange of Notes between the UK Government and each of the key OTs and the CDs. ${ }^{31}$ In each Note, the UK and respective government (referred to as the "Participants") recognised:

"the importance of the provision of beneficial ownership information for the prevention and detection of corruption, money laundering, terrorism financing, financing of the proliferation of weapons of mass destruction and other serious and organised crime". 32

Each individual Note focuses on three key commitments by each of the Participants:

i) To provide the law enforcement authorities of the other Participant with beneficial ownership information for corporate and legal entities incorporated in their respective jurisdiction;

ii) To hold adequate, accurate and current beneficial ownership information for corporate and legal entities incorporated in their own jurisdictions; and

iii) To give law enforcement authorities of the Participants the "automatic" right to the provision of unrestricted and timely (within twenty-four hours or, where urgently required, within an hour) beneficial ownership information held in the other jurisdiction. ${ }^{33}$

This is a startling development, especially given the fact that previously, such information could only be requested by the UK via the mutual legal assistance process.

These commitments were made having regard to the FATF and G20 initiatives and the UK Government's decision to introduce a public central register of beneficial ownership. ${ }^{34}$

The Exchange of Notes therefore provides for the "timely, safe and secure access for law enforcement [and tax] authorities to beneficial

${ }^{31}$ Beneficial Ownership: Exchange of Notes between the UK Government, Overseas Territories and Crown Dependencies.

${ }^{32}$ See Exchange of Notes between the Government of the United Kingdom and the Government of the Cayman Islands in respect of the sharing of beneficial ownership information, para 2.

${ }^{33}$ A Technical Protocol is attached to each Exchange of Notes setting out the practicalities of the arrangements (the Technical Protocol).

${ }^{34}$ See Technical Protocol, para 3. 
ownership information", with the security of the request and information being provided specifically provided for in each Note. ${ }^{35}$ It remains to be seen whether any legal challenges arise from the exchange of beneficial ownership information in this manner, especially given the time-frame in which the information can be demanded. ${ }^{36}$

Since then, the OTs and CDs have reportedly made "significant progress in implementing the commitments by introducing legislation and establishing, where they did not already exist, central registers or similar effective systems". ${ }^{37}$ This represents a major step forward in assisting law enforcement agencies and tax authorities identify the ultimate beneficial ownership of companies registered in the OTs and CDs. Indeed the commitments place the OTs and CDs ahead of most other jurisdictions and also exceed the current FATF requirements. In May 2018, the Minister for Europe and the Americas, Sir Alan Duncan, informed the House of Commons that the arrangements had been used over seventy times and that this beneficial ownership data had "enhanced intelligence leads and investigations on illicit finance". ${ }^{38}$

\section{THE SANCTIONS AND ANTI-MONEY ACT 2018: TOWARDS THE INTRODUCTION OF PUBLIC BENEFICIAL OWNERSHIP REGISTERS}

Whilst making beneficial ownership information available to law enforcement authorities is a major step forward, the Panama Papers disclosures increased the pressure from civil society organisations, in particular, for states to introduce a public registry of beneficial ownership.

\footnotetext{
${ }^{35}$ See Technical Protocol, para 7(vi).

${ }^{36}$ For example, whether the demand meets the criteria for the provision of such information, especially if it is demanded within an hour. For a critical comment see Fillipo Noseda, 'Too much information: When the UK gets it wrong' (2017) 21(2) Jersey and Guernsey Law Review 182 especially at 193-194. The author also asserts that "the UK government managed to strong-arm the Crown Dependencies and a number of Overseas Territories into signing [the Exchange of Notes]" at 189-190.

${ }^{37}$ See statement to the House of Commons by Sir Alan Duncan, Minister for Europe and the Americas, HC Deb 1 May 2018, vol 640 $<$ https:/hansard.parliament.uk/Commons/2018-05-

01/debates/18050126000009/BeneficialOwnershipInOverseasTerritoriesAndCro wnDependencies $>$ accessed 10 July 2018.

38 Ibid.
} 
The UK is the first G20 country to introduce such a register. Section 81 of the Small Business, Enterprise and Employment Act 2015 amended the Companies Act 2006 and requires companies to keep a "register of people who have significant control over the company". A "person with significant control" (PSC) is an individual who meets one or more of the following conditions:

Directly or indirectly holds more than $25 \%$ of shares in the company;

Directly or indirectly holds more than $25 \%$ of voting rights in the company;

Directly or indirectly holds the right to appoint or remove a majority of the directors of the company;

Has the right to exercise, or actually exercises, significant influence or control over the company;

Where a trust or firm would satisfy one of the first four conditions if it were an individual, any individual holding the right to exercise, or actually exercising, significant influence or control over the activities of that trust or firm. This is not limited to the trustee of the trust.

The annual returns by companies (known as "confirmation statements") must contain beneficial ownership details. The register is accessible to the public free of charge. ${ }^{39}$

At that point, the UK Government resisted the idea of imposing similar provisions on the OTs or CDs. In fact some significant progress was later reported by the Overseas Territories Directorate in that several of the OTs and CDs had already established central registers of beneficial ownership or a similar arrangement, although only Montserrat had committed to establish a publicly accessible register. ${ }^{40}$

In 2017 the Sanctions and Anti-Money Laundering Bill was introduced in the House of Lords. This major piece of legislation was

\footnotetext{
${ }^{39}$ For a review of the operation of the register see Global Witness 'In Pursuit of Hidden Owners Behind Companies' (2018)

$<$ https://www.globalwitness.org/en/blog/pursuit-hidden-owners-behind-ukcompanies/> accessed 19 July 2018.

${ }^{40}$ Foreign \& Commonwealth Office, Overseas Territories Directorate Freedom of Information Act 2000 Request Ref: 0896-17: 'Overseas Territories and Crown Dependencies 2017' 8 February 2018

ttps://assets.publishing.service.gov.uk/government/uploads/system/uploads/attach ment_data/file/679038/FOI_0896-17_response.pdf> accessed 20 July 2018. In fact Jersey established a central register of current beneficial ownership in 1989 as did Bermuda in 1981.
} 
designed, amongst other things, to prevent money laundering through the use of Scottish Limited Partnerships and to provide power to impose sanctions on individuals for the purpose of preventing, or in response to, a gross human rights abuse or violation. ${ }^{41}$

Originally it contained no provision relating to the establishment of public beneficial ownership registers in the OTs and CDs and an amendment to do so was rejected by the Government. Lord Ahmad of Wimbledon stated that it was only in exceptional circumstances that the UK would legislate for the OTs without their consent and that the Government wished "to take action within the existing framework of friendly cooperation, building on progress already made". ${ }^{42} \mathrm{He}$ also pointed out that the FATF Recommendations did not require such registers but that the OTs would comply if these became an internationally required standard. In the House of Commons, this point was reiterated by Sir Alan Duncan, the Minister for Europe and the Americas, who made it clear that the UK Government "would have preferred to work consensually with the overseas territories to make those registers publicly available, as we have done in agreeing the Exchange of Notes process". 43

However in the House of Commons at the Report Stage, a group of MPs from all three main political parties tabled amendments to the Bill requiring the UK Government to enforce public registers on the OTs and the CDs by the end of 2020. Without an absolute majority in the House of Commons, the Government decided to concede the point as regards the OTs (but not the CDs) to enable the enactment of the Bill on schedule. ${ }^{44}$ Sir Alan Duncan informed the House of Commons that the UK Government recognised the majority view and would not oppose the amendment, this despite his view that legislating directly would damage the autonomy of the OTs. ${ }^{45}$

The Act came into force on May 23 2018. Section 51 is headed "Public registers of beneficial ownership of companies registered in British Overseas Territories" and provides as follows:

\footnotetext{
${ }^{41}$ Popularly known as the Magnitsky amendment.

${ }^{42}$ HL Deb 6 December 2017, c1117.

${ }^{43}$ HC Deb (n 37) 21.

${ }^{44}$ As Andrew Mitchell MP noted in the House of Commons debate on the Bill, the acceptance by the Government of the new provision "is evidence that, in a hung parliament, power passes from the Cabinet room to the Floor of the House of Commons": HC Deb (n 37) 41.

${ }^{45}$ HC Deb (n 43).
} 
"(1) For the purposes of the detection, investigation or prevention of money laundering, the Secretary of State must provide all reasonable assistance to the governments of the British Overseas Territories to enable each of those governments to establish a publicly accessible register of the beneficial ownership of companies registered in each government's jurisdiction". ${ }^{46}$

Such register is to be broadly in line with the UK provisions, noted earlier. ${ }^{47}$

Mindful of the reluctance that some OTs might display in establishing such a register, section 51(2) carries a threat in that:

"The Secretary of State must, no later than 31 December 2020, prepare a draft Order in Council requiring the government of any British Overseas Territory that has not introduced a publicly accessible register of the beneficial ownership of companies within its jurisdiction to do so".

Not surprisingly, the reaction from some OTs was very critical of these provisions with two main concerns being raised.

Firstly, the fact that a public register would put the OTs at an economic disadvantage in relation to other off-shore jurisdictions, such as Delaware and Panama, which do not have such a register. It was argued that inevitably this would lead to individuals moving their companies elsewhere and thus have a negative impact on the financial and corporate services provided by the OTs. This is an understandable concern although it is perhaps unlikely that this will significantly affect those who are using these services for legitimate purposes. Of course the only way to resolve this concern conclusively is to establish a level playing field with the global introduction of such registers. This is considered further in the next section.

Secondly, the threat of an Order in Council to impose a register of beneficial ownership on the OTs undermines the right of the OTs to internal self-government. Sir Alan Duncan in the House of Commons

46 s49(3) provides that "Money laundering" has the meaning given by the Proceeds of Crime Act 2002, s 340(11).

${ }^{47} \mathrm{~s} 22(7)$ provides that "a "publicly accessible register of the beneficial ownership of companies" means a register which, in the opinion of the Secretary of State, provides information broadly equivalent to that available in accordance with the provisions of Part 21A of the Companies Act 2006". 
noted that "Her Majesty's Government are acutely conscious of the sensitivities in the overseas territories that the new [section] may provoke".

Indeed, criticism of the Act was soon forthcoming from the OTs. For example, in a Statement issued on 23 May 2018 the Premier of the British Virgin Islands said: "We are deeply disturbed by the decision in the United Kingdom which threatens to impose public registers on the BVI.... The Government of the Virgin Islands is committed to pursuing all available legal channels to ensure that publicly available beneficial ownership registers are introduced in the BVI only if and when they become a global standard, which would establish a level playing field for all.... According to the rule of law and the BVI's constitution, the fundamental rights of privacy of all persons, including citizens and corporate entities, must be protected and upheld". ${ }^{48}$ Given the revelations from the Panama Papers, any efforts by the OTs to prevent public disclosure of beneficial ownership suggests that they have something to hide.

From a constitutional perspective, the use of Orders in Council to address UK concerns and requirements in the OTs is not uncommon. For example the UK abolished capital punishment as well as discrimination on grounds of sexuality in the OTs by way of Orders in Council. Perhaps the most notable example came in 2009 when an Order in Council was published ${ }^{49}$ effectively suspending the Government of the Turks \& Caicos Islands and vesting its powers in the Governor. This followed a report by Sir Robin Auld which found that there was "a high probability of systematic corruption in government and the legislature and among public officials" in the Islands. This led to the making of the Turks and Caicos Islands Constitution Order $2011^{50}$ which increased control of the UK over the islands. In particular section 14 provides:

"Her Majesty reserves to Herself power, with the advice and consent of Her Privy Council, to make laws for the peace, order and good government of the Turks and Caicos Islands". ${ }^{51}$

\footnotetext{
${ }^{48}$ See DS Smith, 'Statement by Premier on the Royal Assent of the Sanctions and Anti-Money Laundering Bill' (Government of the Virgin Islands, 23 May 2018) $<$ http://www.bvi.gov.vg/media-centre/statement-premier-royal-assent-sanctionsand-anti-money-laundering-bill $>$ accessed 28 July 2018.

49 The Turks \& Caicos Islands Constitution (Interim Amendment) Order 2009 placed before Parliament on 25 March 2009.

${ }^{50}$ SI 1681 of 2011.

${ }^{51}$ For a detailed discussion of the case see Nicholls and others (n 5) paras 11.74 et seq.
} 
Making laws designed to help combat money laundering, tax evasion and the financing of terrorism is clearly a matter of good governance and requiring each OT to establish and maintain a public record of beneficial ownership falls directly into this category.

It is also worth repeating the view of the UK Government in the OT White Paper that "As a matter of constitutional law the UK Parliament has unlimited power to legislate for the Territories".

During the parliamentary debate on the Bill, a clause requiring the introduction of a similar provision for the CDs was withdrawn. This was in recognition of the very different constitutional relationship between the $\mathrm{UK}$ and the CDs, noted earlier. Thus the requirement for public registers does not currently extend to the CDs.

\section{CONCLUSION}

The ongoing work of the FATF and G20 highlights the fact that developing transparency in the beneficial ownership of companies is now a global issue in the fight against money laundering, tax evasion, terrorist financing and other serious crime. A key goal in this regard is for tax authorities and law enforcement agencies to have "adequate and timely information on the beneficial ownership and control of legal persons". ${ }^{52}$ This is facilitated by the effective exchange of beneficial ownership information between jurisdictions. Given their position as major offshore financial centres, the OTs and CDs play a key role especially as each is a separate jurisdiction for the purposes of mutual legal assistance requests. The Exchange of Notes between the UK and the OTs and CDs is therefore an important, and seemingly effective, contribution to this goal. The process provides an excellent example for all jurisdictions to follow and one that the FATF and G20 should continue to actively encourage.

The introduction in the Sanctions and Anti-Money Laundering Act 2018 of a requirement for the OTs to introduce a public register of beneficial ownership is far more controversial. The need to address the issue is certainly urgent given the fact that, as noted earlier, £90 billion is reportedly laundered through the UK each year with the OTs being "central to this nefarious activity". However, the use of the 2018 Act to impose the will of the UK Parliament on the OTs through an Order in Council, if necessary, highlights the uncertain constitutional relationship between the UK and OTs. Clegg notes that the current arrangements, at least so far as the Caribbean OTs are concerned, were not intended to be

${ }^{52}$ FATF Recommendation 24: see the discussion in Section 2 above. 
permanent but were originally proposed as stepping stones en route to independence. Thus the balance of administrative responsibilities is in practice often ill-defined. ${ }^{53}$ As he also notes, it is open to any OT to move towards full independence, if so desired. Whilst this issue is beyond the scope of this note, it may be pointed out that the OTs have benefited greatly economically from their continued association with the UK, especially as compared to those former colonies which chose to become independent states. Whatever the future constitutional relationship between the UK and OTs, the key point is that a public register of beneficial ownership must become a global standard and this is where the FATF, with its global reach, must take swift action.

So far as the CDs are concerned, EU Directives and Regulations relating to financial services, economic and monetary union and taxation do not apply there. ${ }^{54}$ Thus they do not fall within the scope of the EU $5^{\text {th }}$ Anti-Money Laundering Directive which was published on 19 June 2018 and entered into force on July 92018 . Amongst other things, the Directive (which was partly influenced by the publication of the Panama Papers) requires all states to allow "any member of the general public" access to beneficial ownership registers to obtain information concerning the beneficial owner's month and year of birth, country of residence, and nationality, as well as the nature and extent of the beneficial interest held. Member states are obliged to transpose the regulations into national law by January 202020 . In practice the CDs have opted to follow many aspects of EU legislation and standards. Given the continued importance of the corporate and financial sectors in the CDs, complying with the EU anti-money laundering requirements may well become necessary.

In the UK context, the ability of tax authorities and law enforcement agencies to obtain access to beneficial ownership information from the OTs and CDs enhances the prospect of identifying the person "with significant control" of a shell or shelf company. Using the Land Registry records which provide information about the legal ownership of real estate, many of which are companies registered in off-shore jurisdictions, it becomes possible to link the legal ownership of property to the beneficial owner(s). If this is a foreign politically exposed person (PEP) ${ }^{55}$

\footnotetext{
${ }^{53}$ See Peter Clegg (n 3) 2.

${ }^{54}$ Home Office, Review of Financial Regulation in the Crown Dependencies (Cm 4109-I, 1998) para 5.3.5.

55 The Proceeds of Crime Act 2002, s 362B(7) Inserted by the Criminal Finances Act 2017, states that a "politically exposed person means a person who is-
} 
or one of their family members or close associates, this will allow the UK law enforcement authorities to consider applying for an unexplained wealth order (UWO). Such an order requires the PEP to explain the legitimate source(s) of their wealth. The adequacy of the response or a refusal to provide such information can then be taken into account in any later civil recovery proceedings. ${ }^{56}$

Given the importance of the contribution of civil society organisations (CSOs) such as Global Witness and Transparency International in highlighting and campaigning for transparency in beneficial ownership, the passing of the 2018 Act is a major success. It also offers them the prospect of enhancing their work, and that of other CSOs, on identifying the beneficial ownership of property and enhancing further the fallout from the Panama Papers.

(a) an individual who is, or has been, entrusted with prominent public functions by an international organisation or by a State other than the United Kingdom or another EEA State,

(b) a family member of a person within paragraph (a),

(c) known to be a close associate of a person within that paragraph, or

(d) otherwise connected with a person within that paragraph".

${ }^{56}$ See Criminal Finances Act 2017, ss 1-6. 